\title{
Preliminary Analysis of CyberKnife Stereotactic Radiotherapy for Primary and Recurrent Head and Neck Cancers: A Delicate Balance
}

Trinanjan Basu ${ }^{1}$, Tejinder Kataria ${ }^{2}$, Shikha Goyal ${ }^{3}$, Deepak Gupta ${ }^{4}$

\begin{abstract}
Introduction: This is a preliminary analysis of CyberKnife (CK) stereotactic body radiotherapy (SBRT) among the Indian head and neck cancer (HNC) population. Forty-one patients (27 recurrent and 14 primary) were selected and grouped into group I (re-irradiation $=26)$ and group II [recurrent RT naïve or CK boost after volumetric modulated arc therapy (VMAT)/intensity-modulated radiotherapy (IMRT) $=15$ ]. Histological types included squamous cell carcinoma (38) and adenoid cystic carcinoma (3).

Materials and methods: Univariate and multivariate analyses for disease-free survival (DFS) and overall survival (OS) were performed using disease group, median tumor volume, median tumor size, positron emission tomography (PET)-CT median SUVmax, and post-CK response category. Kaplan-Meier survival and Cox proportional ratios were used using SPSS version 19.0.

Results: After a median follow-up of 25 months (range: 0-39 months), all patients combined the 2 years OS and DFS were 92 and $45 \%$, respectively. The median OS and DFS were 25 and 10 months among the cohort. Group I had II years OS and DFS of 85 and $25 \%$, respectively, whereas group II had 2 years OS and DFS 98 and 45\%, respectively. Till the last follow-up, 33 patients were alive and 5 were lost to follow-up. Eight patients in group I and only one patient in group II had disease progression. Eleven patients in group I and 12 patients in group II had partial to complete response. The median tumor volume was $29.8 \mathrm{~cm}^{3}$ and was found to be a strong statistically significant factor for DFS in univariate $(p=0.007)$ analysis. Treatment was well tolerated with only three-grade IV toxicities.

Conclusion: CyberKnife SBRT is an attractive option for both recurrent and primary HNC. A delicate balance needs to be maintained between disease control and major adverse events.

Keywords: CyberKnife, Radiosurgery, Recurrent head and neck cancer, Survival.

International Journal of Head and Neck Surgery (2021): 10.5005/jp-journals-10001-1425
\end{abstract}

\section{INTRODUCTION}

Multimodality treatment encompassing surgery, radiotherapy, and chemotherapy improved the disease control and survival rates in locally advanced head and neck cancers (HNCs). ${ }^{1-3}$ Treatment of recurrent disease, however, in the setting of re-irradiation, second primary HNC in adjacent regions, and primary tumors overlapping with critical organs hindering radical dose delivery remains a challenge. Stereotactic body radiotherapy (SBRT) in extracranial disease sites with CyberKnife (CK) robotic radiosurgery (Accuray, Sunnyvale, CA, USA) has been a delicate balance in this scenario., ${ }^{4,5}$

We have previously published our data on CK boost among primary HNC patients. ${ }^{6}$ This is the next step in reporting CyberKnife SBRT (CK-SBRT) among both recurrent and primary HNC boost patients in the Indian scenario.

\section{Materials and Methods}

\section{Patient Characteristics}

Forty-one HNC patients were given CK-SBRT between December 2012 and December 2015. CyberKnife SBRT was considered after careful consideration of other treatment options like surgery, conventional radiotherapy, or chemotherapy through a multidisciplinary tumor board clinic. There were two groups of patients: (1) recurrent HNC (primary or nodal) or second primary, usually after one course of irradiation for primary disease, (2) primary HNC managed with radiation or chemoradiation, where the tumor location precluded radical dose delivery to gross disease due to high risk of toxicity, hence CK boost was considered after

\footnotetext{
${ }^{1-4}$ Department of Radiation Oncology, Medanta-The Medicity Hospital, Gurugram, Haryana, India

Corresponding Author: Trinanjan Basu, Department of Radiation Oncology, Medanta-The Medicity Hospital, Gurugram, Haryana, India, Phone: +91 9811379713, e-mail: trinanjan.doctor@gmail.com

How to cite this article: Basu T, Kataria T, Goyal S, et al. Preliminary Analysis of CyberKnife Stereotactic Radiotherapy for Primary and Recurrent Head and Neck Cancers: A Delicate Balance. Int J Head Neck Surg 2021;12(2):43-47.

Source of support:The work was done at Radiation Oncology, MedantaThe Medicity, Gurugram, India, and no separate funding was allocated. Conflict of interest: None
}

external beam radiotherapy up to a certain dose level. Treatment and its possible complications were obtained as informed consent from patients before CK-SBRT.

Table 1 depicts the characteristics of patients and tumors. The cohort consisted of 27 males and 14 females, with a median age of 55 years (range: $10-89$ years). Group I had 26 patients (loco-regional recurrence: 15 , nodal recurrence: 9 , second primary: 3 , and distant nodal recurrence: 1), 14 of whom had received prior irradiation. The median interval between initial radiation and CK-SBRT was 18 months (range: 3-170 months). Six patients were in group II (CK boost in view of proximity to the visual pathway, brainstem, or mandible). Histological types were squamous cell carcinoma $(n=20)$ and adenoid cystic carcinoma $(n=2)$. 
Table 1: Patient and disease characteristics

\begin{tabular}{|c|c|}
\hline Characteristics & Value (\%) \\
\hline Number & $41(100 \%)$ \\
\hline \multirow[t]{2}{*}{ Age } & Median: 46.5 years \\
\hline & Range: $10-83$ years \\
\hline \multirow[t]{2}{*}{ Gender } & Male: 16 (72.7\%) \\
\hline & Female: 6 (27.3\%) \\
\hline \multirow[t]{4}{*}{ Comorbidities } & $\begin{array}{l}\text { Hypertension and diabetes: } 3 \\
(13.6 \%)\end{array}$ \\
\hline & Hypertension: 1 (4.5\%) \\
\hline & Hypothyroid: 1 (4.5\%) \\
\hline & None: 17 (77.3\%) \\
\hline \multirow[t]{3}{*}{ Addiction } & Tobacco: 6 (27.3\%) \\
\hline & Smoking: 2 (9.1\%) \\
\hline & No addiction: 14 (63.6\%) \\
\hline \multirow[t]{12}{*}{ Primary diagnosis } & Oral cavity: 8 (36.3\%) \\
\hline & Tongue: 5 \\
\hline & RMT: 2 \\
\hline & GB sulcus: 1 \\
\hline & Oropharynx: 4 (18.1\%) \\
\hline & Soft palate: 2 \\
\hline & BOT: 1 \\
\hline & Tonsil: 1 \\
\hline & Nasopharynx: 5 (22.7\%) \\
\hline & Hypopharynx: 2 (9\%) \\
\hline & Larynx: 1 (4.5\%) \\
\hline & Adenoid cystic: 2 (9\%) \\
\hline \multirow[t]{2}{*}{ Recurrence } & Yes: 15 (68.2\%) \\
\hline & No: 7 (31.8\%) \\
\hline \multirow[t]{2}{*}{ Re-radiation } & Yes: 14 (63.6\%) \\
\hline & No: 8 (36.4\%) \\
\hline \multirow[t]{4}{*}{ Recurrent disease site } & Loco-regional: 6 \\
\hline & Nodal: 7 \\
\hline & 2nd HN primary: 2 \\
\hline & HN primary with distant node: 1 \\
\hline \multirow[t]{2}{*}{ Diagnosis of recurrence } & On PETCT: 6 \\
\hline & Biopsy/FNAC: 10 \\
\hline \multirow[t]{2}{*}{ CyberKnife radiotherapy intent } & CyberKnife SBRT alone: 13 (59.1\%) \\
\hline & $\begin{array}{l}\text { Primary RT with CK boost: } 9 \\
(40.9 \%)\end{array}$ \\
\hline \multirow[t]{2}{*}{ Gap between 1st and 2nd RT } & Median: 18 months \\
\hline & Range: 3-170 months \\
\hline
\end{tabular}

\section{Treatment Procedure}

The CK-SBRT procedure consists of four steps viz thermoplastic mold preparation, CT simulation image acquisition, treatment planning, and delivery. CT simulation scans with intravenous contrast of $1 \mathrm{~mm}$ slice thickness from the top of the skull to the thoracic inlet, ensuring at least $10 \mathrm{~cm}$ margin cranially and caudally from the gross disease. DICOM images were imported into the CK treatment planning system (Multiplan) and additional images viz magnetic resonance imaging (MRI) in all cases and diagnostic positron emission tomography (PET)-CECT were used in consultation with a radiologist. The gross tumor volume (GTV) was
Table 2: Treatment characteristics

\begin{tabular}{|c|c|}
\hline Characteristics & Value \\
\hline \multirow[t]{2}{*}{ Recurrent disease dimension } & Median: $2.9 \mathrm{~cm}$ \\
\hline & Range: $1.8-5.5 \mathrm{~cm}$ \\
\hline \multirow[t]{2}{*}{ Gross tumor volume (in $\mathrm{cm}^{3}$ ) } & Median: 29.8 \\
\hline & Range: $7.2-243$ \\
\hline \multirow[t]{2}{*}{ Recurrent disease PET-CT SUVmax } & Median: 15.8 \\
\hline & Range: $6.1-28.04$ \\
\hline \multirow[t]{2}{*}{ CyberKnife dose per fraction (in Gy) } & Median: 6 \\
\hline & Range: 3-12 \\
\hline \multirow[t]{2}{*}{ Number of fractions } & Median: 5 \\
\hline & Range: $2-7$ \\
\hline \multirow[t]{2}{*}{ Conformity index $(\mathrm{Cl})$} & Median: 1.8 \\
\hline & Range: $1.1-11.9$ \\
\hline \multirow[t]{2}{*}{ Treatment time (in minute) } & Median: 46 \\
\hline & Range: $23-68$ \\
\hline \multirow[t]{2}{*}{ New conformity index $(\mathrm{nCl})$} & Median: 1.9 \\
\hline & Range: $1.1-11.9$ \\
\hline \multirow[t]{2}{*}{ Homogeneity index (HI) } & Median: 1.28 \\
\hline & Range: $1.12-1.43$ \\
\hline \multirow[t]{2}{*}{ Prescription isodose } & Median: 78\% \\
\hline & Range: $70-89 \%$ \\
\hline
\end{tabular}

the visible tumor in the imaging studies. Planning target volume (PTV) of 3-5 mm was given for anticipated internal physiological variations like respiration and swallowing movements. Inverse planning computer algorithm determined the number, direction, and duration of treatment beams. The total dose and the fractional dose were customized as per tumor volume, prior radiotherapy to current CK-SBRT duration and proximity to organs at risk, and the patient's general condition. No patients received chemotherapy concurrent with CK-SBRT.

The median dose of $6 \mathrm{~Gy}$ per fraction and a median of 5 fractions (range: 3-7 fractions) prescribed to $90 \%$ of the PTV (D90) was most common. The most frequent regimen was $30 \mathrm{~Gy}$ in 5 fractions prescribed to $70-90 \%$ isodoses for recurrent HNC patients. For CK-SBRT boost, most patients received 3 fractions of 3-9 Gy per fraction. The median target volume was $29.8 \mathrm{~cm}^{3}$ (range: $7.2-243$ $\mathrm{cm}^{3}$ ) and the median treatment duration was 5 days (range: 3-7 days). The biological effective dose (BED) was calculated by a linearquadratic model using the $\alpha / \beta$ ratio of $10 \mathrm{~Gy}$ for tumor effects and based on D90 and D100.

During the treatment delivery, two orthogonal diagnostic X-ray cameras provided real-time images of the patient's anatomy. Either skull or spine tracking was applied for the tumor motion. Median treatment duration was 46 minutes per fraction (range: 23-68 minutes), depending on the dose per fraction, the number of beam nodes, and patient's compliance. The treatment was performed on consecutive days except for public holidays. Table 2 summarizes the treatment-related parameters.

\section{Toxicity Evaluation}

The acute and late morbidities were recorded using the Radiation Therapy Oncology Group (RTOG) acute and late morbidity scoring criteria. The major adverse events (RTOG grade III or more) are depicted in Table 3. 


\section{Statistical Analysis}

The statistical analyzes were performed using SPSS version 18.0. The last follow-up status was noted from the last fraction of CK-SBRT to the last date of follow-up and all patients having a stable disease and above were taken as locally controlled. For objective local assessment, both RECIST and PERCIST (PET-based response evaluation) criteria were utilized. Univariate and multivariate analyzes for determining disease-free survival (DFS) taken into account the median tumor volume and tumor size, median SUVmax in PET-CT, the interval between primary RT and CK-SBRT, and site of disease.

\section{Results}

\section{Treatment Results}

Median follow-up after CK-SBRT was 9.5 months (range: 6-21 months). Loco-regional response rates were calculated based on radiographic and clinical assessment (Table 4). Nine and five patients in groups I and II, respectively, had loco-regionally stable disease (Fig. 1). Four patients in group I and one in group II had local progression, while one patient in group II had distant metastasis. A follow-up imaging assessment was not available in three patients from group I as they were lost to follow-up. Objective local response was evaluated as per RECIST criteria and eight patients had a complete response (four in each group), while four patients each in group I had a partial response and progressive disease respectively and three patients were lost to follow-up till last visit. ${ }^{7}$

Median values for maximum gross tumor dimension, GTV, and SUVmax were $2.9 \mathrm{~cm}, 29.8 \mathrm{~cm}^{3}$, and 15.8 , respectively. On univariate analysis patients with median tumor volume, $<29.8 \mathrm{~cm}^{3}$ had

Table 3: Clinical outcome and response to CyberKnife stereotactic body radiotherapy (SBRT)

\begin{tabular}{lll}
\hline Characteristics & Group I (16) & Group II (6) \\
\hline Post-CyberKnife imaging & 13 & 6 \\
$\quad$ Available & 3 & 0 \\
$\quad$ Evaluation pending/not available & & \\
Status after CyberKnife SBRT & & 5 \\
Loco-regionally stable & 9 & 0 \\
Local progression & 4 & 1 \\
Distant metastasis & 0 & 0 \\
Not known & 3 & \\
Local response after CyberKnife SBRT & & 4 \\
CR & 4 & 1 \\
PR & 4 & 0 \\
SD & 1 & 1 \\
PD & 4 & 0 \\
Lost to FU & 3 & \\
\hline
\end{tabular}

statistically significant better DFS ( $p$ value $=0.007$ ) and response rates $(100 \%$ in each group at 6 months and 100 vs $55 \%$ at 1 year and 100 vs $25 \%$ at 1.5 years). Other factors analyzed for DFS were statistically not significant. Site of recurrence had no statistically significant impact on outcome but patients having second primary and nodal recurrence had a trend toward better DFS than locoregional recurrence (at 1-year loco-regional recurrences had 50\% DFS while nodal and 2nd primary together had 70\% DFS). There was no impact of re-radiation duration or re-radiation per se upon DFS statistically. No factors were statistically significant in multivariate analysis. After a median follow-up of 9.5 months, complete response rates were observed more frequently in both the groups (four in each group) and four more patients had a partial response in group I. Though statistically non-significant but factors like smaller tumor volume at recurrence, the greater time interval between first and second RT courses and nodal recurrence and 2nd primaries showed a better response and local control rates. The details have been elucidated in Table 4.

\section{Complications}

All patients completed the CK-SBRT schedule without interruption. Three patients reported early onset late complications between 2 and 4 months after CK-SBRT. One had RTOG grade IV neck stiffness needing morphine, muscle relaxants, and physiotherapy, another had grade IV trismus needing percutaneous gastrostomy feeding tube placement and the third patient had external carotid artery bleed, that was salvaged successfully with emergency arterial angioembolization. All of them were re-irradiation with a minimum gap between the two courses was 20 months (Table 3).

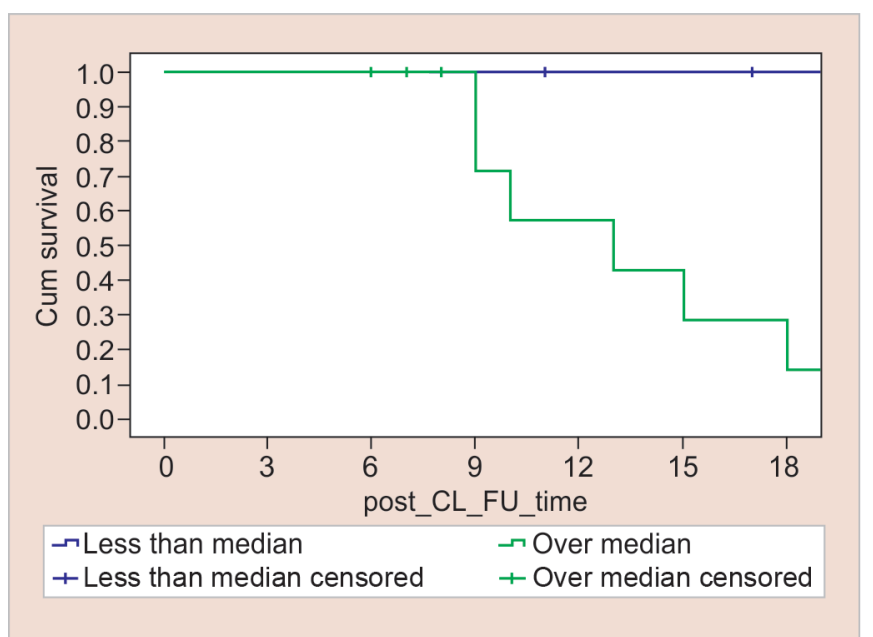

Fig. 1: Radiological assessment pre- and post-CyberKnife stereotactic body radiotherapy

Table 4: Important adverse features with CyberKnife stereotactic body radiotherapy (re-irradiation $n=14$ )

\begin{tabular}{|c|c|c|c|c|c|c|c|}
\hline Patient & $\begin{array}{l}\text { Primary } \\
\text { diagnosis }\end{array}$ & $\begin{array}{l}\text { Recurrence } \\
\text { treatment site }\end{array}$ & $\begin{array}{l}\text { Previous } \\
\text { RT dosage }\end{array}$ & $\begin{array}{l}\text { Gap between } \\
\text { 1st and } 2 \text { nd RT }\end{array}$ & $\begin{array}{l}\text { CyberKnife RT dose } \\
\text { (Gy/fraction) }\end{array}$ & $\begin{array}{l}\text { Major adverse event } \\
\text { (onset time/RTOG grade) }\end{array}$ & $\begin{array}{l}\text { Last follow-up } \\
\text { status }\end{array}$ \\
\hline 31 years/F & $\begin{array}{l}\text { Carcinoma } \\
\text { nasopharynx }\end{array}$ & $\begin{array}{l}\text { Locally recurrent } \\
\text { nasopharynx }\end{array}$ & $70 \mathrm{~Gy}$ & 77 months & $30 / 5$ & $\begin{array}{l}\text { Severe neck pain ( } 2 \\
\text { months/grade III) }\end{array}$ & $\begin{array}{l}\text { Under narcotic } \\
\text { analgesics }\end{array}$ \\
\hline 59 years/M & $\begin{array}{l}\text { Carcinoma } \\
\text { tongue }\end{array}$ & Local recurrence & $64 \mathrm{~Gy}$ & 20 months & $38.5 / 7$ & $\begin{array}{l}\text { Severe trismus ( } 2 \\
\text { months/grade IV) }\end{array}$ & $\begin{array}{l}\text { Pall chemo } \\
\text { in view SD to } \\
\text { treatment }\end{array}$ \\
\hline 72 years/F & $\begin{array}{l}\text { Carcinoma } \\
\text { tongue }\end{array}$ & $\begin{array}{l}\text { Parapharyngeal } \\
\text { recurrence }\end{array}$ & $64 \mathrm{~Gy}$ & 42 months & $30 / 5$ & $\begin{array}{l}\text { Right ECA bleed ( } 4 \\
\text { months/grade IV) }\end{array}$ & $\begin{array}{l}\text { Salvage with an- } \\
\text { gioembolization }\end{array}$ \\
\hline
\end{tabular}




\section{Discussion}

This study reported the use of CK-SBRT for both previously irradiated and de novo HNC patients. With the limitations of salvage surgery, poor benefit from systemic agent high-dose radiation therapy has come into the horizon for the last couple of years. ${ }^{8-12}$ Though there are no prospective data comparing re-irradiation using conventional fractionation intensity-modulated radiotherapy (IMRT) with SBRT, it has some clear advantages like noninvasive immobilization, short treatment duration, tumor tracking, and correction in real-time. ${ }^{11,13,14}$ Low dose rate brachytherapy has been used to increase the dose prescription to the primary tumor in the head and neck region with excellent local control rates. ${ }^{15}$ CyberKnife SBRT expands the armamentarium of a radiation oncologist to include conformal radiation with sharp gradients in the regions where the placement of catheters for brachytherapy is a challenge.

The dose prescription with CK-SBRT in our series corroborated with World literature and most patients in the re-irradiation group had 5 fractions with 5-6 Gy per fraction keeping in mind the previous dosage, time elapsed and OAR's tolerances. ${ }^{11,16,17}$

Wu et al. reported their experience of SBRT for salvage of local failure in 90 patients with persistent or recurrent nasopharyngeal cancer. The median dose was either $18 \mathrm{~Gy}$ in three fractions for the persistent group or $48 \mathrm{~Gy}$ in six fractions for the recurrent group. The complete response rate was $66 \%$ for the persistent group and $63 \%$ for the recurrent group. Disease-specific survival and progression-free survival rates for all patients after 1, 2, and 3 years were $82.6,74.8,57.5 \%$ and $72.9,60.4,54.5 \%$, respectively. Kodani et al. also reported the effectiveness of re-irradiation with CK-SBRT for the treatment of head and neck tumors. The overall response rates were $61.9 \%$ and the 2 -year overall survival (OS) rate was $50 \%$.

Recent literature also evaluated the role of CK-SBRT as a boost treatment. Siddiqui et al. have indicated that SBRT was effective as definitive therapy for selected patients. ${ }^{11,18}$ Uno et al. also reported for 10 patients the role of CK-SBRT boost in view of tumors close to the optic pathway, brainstem, or mandible. After a median follow-up of 6 months, six patients showed complete response and only three patients had grade III oral mucositis. ${ }^{19}$ Similarly, Le et al. reported excellent local control, $100 \%$ at 3-year, with acceptable late toxicities in 45 patients of nasopharyngeal cancer who received SBRT boost, and 12 patients were treated with CK-SBRT. ${ }^{20}$ We have also published CK boost data in line with World literature. ${ }^{6}$

The prognostic importance of tumor volume in SBRT is widely reported. Wu et al. reported larger tumor volume resulted in both poorer disease-specific survival and progression-free survival. ${ }^{21}$ The reason was a higher risk of distant failure for the larger tumor group and speculated that additional chemotherapy might improve survival. In our data median, tumor volume for the recurrent disease was $29.8 \mathrm{~cm}^{3}$ and when analyzed between the groups both univariate and multivariate results were significant for DFS. A similar study from Pittsburgh also reported tumor volume $<25 \mathrm{~cm}^{3}$ and 5 fractions of SBRT as a suitable regimen for recurrent HNC. ${ }^{22}$

Literature suggests that prior radiotherapy within 24 months results in an inferior OS. ${ }^{18,23}$ This cohort consisted of relatively early recurring and high-grade tumors. In our cohort of patients with early outcome analysis, the median gap between 1st and 2nd radiation was 18 months and at 1 year though the results remain statistically non-significant, with $>2$ years gap between two radiotherapy schedules a better survival (65 vs $55 \%$ ) was observed. ${ }^{12,24-26}$ The definite time period between two courses of radiotherapy, although debatable but most authors agree on a minimum gap of 6 months. ${ }^{12,23,27}$ It has been suggested that the longer the interval, the greater the likelihood of local control and fewer the complications.

Our study had its own set of limitations like a nonrandomized heterogeneous cohort of patients, treatment at a single institution, toxicities were determined based on chart reviews, and a short median follow-up of 6 months enabling incomplete assessment of the long-term complications due to re-irradiation in all patients.

However, it offers definite advantages over conventional fractionated radiation therapy and is a viable option for patients who are progressing/relapsed after surgery or chemotherapy or prior radiotherapy. The other alternative for these patients was the end of life care with pain management and other palliative measures. The practical advantage of only a 1-week treatment with good palliation of debilitating symptoms is a definite advantage. We would require more clinical experience coupled with longer follow-up to validate our results. Finally, we believe CK-SBRT for $\mathrm{HNC}$ will emerge as a standard of care in near future.

\section{Conclusion}

CyberKnife SBRT is an effective option for both recurrent and primary HNC. With the limited number of patients and limited follow-up data, the early results are quite encouraging. However, the dilemma between disease control and major adverse events indeed makes it a tight rope walk. Future prospective studies with longer follow-up might resolve hitherto unanswered issues.

\section{Acknowledgments}

All the faculty members of our department, technical and physics team, and above all our patients need acknowledgment. There was neither any financial support for the study nor the authors have any conflict of interest to declare.

\section{Ethical Approval}

All the applicable Institutional guidelines were followed. All procedures were as per the Ethical standards of the Institution and with the 1964 Helsinki declaration and its later amendments.

\section{Informed Consent}

Informed consent was obtained from all individual participants included in the study.

\section{References}

1. Bernier J, Domenge C, Ozsahin M, et al. Postoperative irradiation with or without concomitant chemotherapy for locally advanced head and neck cancer. N Engl J Med 2004;350(19):1945-1952. DOI: 10.1056/NEJMoa032641.

2. Cooper JS, Pajak TF, Forastiere AA, et al. Postoperative concurrent radiotherapy and chemotherapy for high-risk squamous-cell carcinoma of the head and neck. N Engl J Med 2004;350(19):19371944. DOI: 10.1056/NEJMoa032646.

3. Bonner JA, Harari PM, Giralt J, et al. Radiotherapy plus cetuximab for squamous-cell carcinoma of the head and neck. N Engl J Med 2006;354(6):567-578. DOI: 10.1056/NEJMoa053422.

4. Adler JR, Murphy MJ, Chang SD, et al. Image-guided robotic radiosurgery. Neurosurgery 1999;44(6):1299-1306. DOI: 10.1227/00006123-199906000-00079. 
5. Chang SD, Adler JR. Robotics and radiosurgery-the CyberKnife. Stereotact Funct Neurosurg 2001;76(3-4):204-208. DOI: 10.1159/000066719.

6. Kataria T, Basu T, Goyal S, et.al. Preliminary results of CyberKnife stereotactic radiotherapy (SBRT) boost for primary head and neck cancers: Is it the future direction? J Radiother Pract 2015;14(2):187-193. DOI: $10.1017 /$ S1460396914000521.

7. Eisenhauer EA, Therasse P, Bogaerts J, et.al. New response evaluation criteria in solid tumours: revised RECIST guideline (version 1.1). Eur J Cancer 2009;45(2):228-247. DOI: 10.1016/j.ejca.2008.10.026.

8. Bachar GY, Goh C, Goldstein DP, et al. Long-term outcome analysis after surgical salvage for recurrent tonsil carcinoma following radical radiotherapy. Eur Arch Otorhinolaryngol 2010;267(2):295-301. DOI: 10.1007/s00405-009-1070-0.

9. Argiris A, Ghebremichael M, Gilbert J, et al. Phase III randomized, placebo controlled trial of docetaxel with or without gefitinib in recurrent or metastatic head and neck cancer: an eastern cooperative oncology group trial. J Clin Oncol 2013;31(11):1405-1414. DOI: 10.1200/ JCO.2012.45.4272.

10. Soulieres D, Senzer NN, Vokes EE, et al. Multicenter phase II study of erlotinib, an oral epidermal growth factor receptor tyrosine kinase inhibitor, in patients with recurrent or metastatic squamous cell cancer of the head and neck. J Clin Oncol 2004;22(1):77-85. DOI: 10.1200/JCO.2004.06.075.

11. Siddiqui F, Patel M, Khan M, et al. Stereotactic body radiation therapy for primary, recurrent, and metastatic tumors in the head-and-neck region. Int J Radiat Oncol Biol Phys 2009;74(4):1047-1053. DOI: 10.1016/j.jirobp.2008.09.022.

12. Cacicedo J, Navarro A, Alongi F, et.al. The role of re-irradiation of secondary and recurrent head and neck carcinomas. Is it a potentially curative treatment? A practical approach. Cancer Treat Rev 2014;40(1):178-189. DOI: 10.1016/j.ctrv.2013.08.002.

13. Fuks Z, Kolesnick R. Engaging the vascular component of the tumor response. Cancer Cell 2005;8(2):89-91. DOI: 10.1016/j.ccr.2005.07.014.

14. Roh KW, Jang JS, Kim MS, et al. Fractionated stereotactic radiotherapy as reirradiation for locally recurrent head and neck cancer. Int J Radiat Oncol Biol Phys 2009;74(5):1348-1355. DOI: 10.1016/j. ijrobp.2008.10.013.

15. Mazeron JJ, Ardiet JM, Haie-Méder C, et.al. GEC-ESTRO recommendations for brachytherapy for head and neck squamous cell carcinomas. Radiother Oncol 2009;91(2):150-156. DOI: 10.1016/j. radonc.2009.01.005.

16. Mantel F, Flentje M, Guckenberger M. Stereotactic body radiation therapy in the re-irradiation situation--a review. Radiat Oncol 2013;8(1):7. DOI: 10.1186/1748-717X-8-7.
17. Unger KR, Lominska CE, Deeken JF, et al. Fractionated stereotactic radiosurgery for reirradiation of head-and-neck cancer. Int J Radiat Oncol Biol Phys 2010;77(5):1411-1419. DOI: 10.1016/j. ijrobp.2009.06.070.

18. Kodani N, Yamazaki H, Tsubokura T, et al. Stereotactic body radiation therapy for head and neck tumor: disease control and morbidity outcomes. J Radiat Res 2011;52(1):24-31. DOI: 10.1269/jrr.10086.

19. Uno $T$, Isobe $K$, Ueno $N$, et.al. Fractionated stereotactic radiotherapy as a boost treatment for tumors in the head and neck region. J Radiat Res 2010;51(4):449-454. DOI: 10.1269/jrr.10040.

20. Le QT, Tate D, Koong A, et.al. Improved local control with stereotactic radiosurgical boost in patients with nasopharyngeal carcinoma. Int J Radiat Oncol Biol Phys 2003;56(4):1046-1054. DOI: 10.1016/S03603016(03)00117-2.

21. Wu SX, Chua DTT, Deng ML, et.al. Outcome of fractionated stereotactic radiotherapy for 90 patients with locally persistent and recurrent nasopharyngeal carcinoma. Int J Radiat Oncol Biol Phys 2007;69(3):761-769. DOI: 10.1016/j.ijrobp.2007.03.037.

22. Rwigema JCM, Heron DE, Ferris RL, et.al. The impact of tumor volume and radiotherapy dose on outcome in previously irradiated recurrent squamous cell carcinoma of the head and neck treated with stereotactic body radiation therapy. Am J Clin Oncol 2011;34(4): 372-379. DOI: 10.1097/COC.0b013e3181e84dc0.

23. Chopra S, Gupta T, Agarwal JP, et al. Reirradiation in the management of isolated neck recurrences: current status and recommendations. Radiother Oncol 2006;81(1):1-8. DOI: 10.1016/j.radonc.2006. 08.017.

24. Mcdonald MW, Moore MG, Peter AS. Risk of carotid blow out after reirradiation of the head and neck: a systematic review. Int J Radiat Oncol Biol Phys 2012;82(3):1083-1089. DOI: 10.1016/j. ijrobp.2010.08.029.

25. Yamazaki H, Ogita M, Kodani N, et.al. Frequency, outcome and prognostic factors of carotid blowout syndrome after hypofractionated re-irradiation of head and neck cancer using CyberKnife: a multi-institutional study. Radiother Oncol 2013;107(3):305-309. DOI: 10.1016/j.radonc.2013.05.005.

26. Spencer SA, Harris J, Wheeler RH, et al. Final report of RTOG 9610, a multiinstitutional trial of reirradiation and chemotherapy for unresectable recurrent squamous cell carcinoma of the head and neck. Head Neck 2008;30(3):281-288. DOI: 10.1002/hed. 20697.

27. Hoebers F, Heemsbergen W, Moor S, et al. Reirradiation for head-andneck cancer: delicate balance between effectiveness and toxicity. Int J Radiat Oncol Biol Phys 2011;81(3):e111-e118. DOI: 10.1016/j. ijrobp.2011.01.004. 